\title{
Effects of Construction Time and Coarse Aggregate on Bridge Deck Cracking
}

\author{
by Kyle A. Riding, Jonathan L. Poole, Anton K. Schindler, Maria C. G. Juenger, and Kevin J. Folliard
}

\begin{abstract}
Bridge deck temperature changes in the first few days after placement due to the concrete heat of hydration and changes in ambient conditions have long been identified as a significant contributor to early-age cracking. The goal of this project was to develop a method of quantifying how materials and construction methods can influence the thermal stresses in bridge decks. A series of tests on concrete mixtures were then performed to quantify the concrete material thermal stress behavior in bridge decks with different placement times and coefficients of thermal expansion. Concrete with a high coefficient of thermal expansion placed in the morning led to the development of thermal stresses equal to $75 \%$ of the stress at cracking. It was also found that the thermal stresses could be reduced by up to $50 \%$ by using concrete with a lower coefficient of thermal expansion and placing at night.
\end{abstract}

Keywords: bridge decks; cracking; thermal stresses.

\section{INTRODUCTION}

Bridge decks are often exposed to large quantities of salts and deicing chemicals. In dense, uncracked concrete, these aggressive agents penetrate into the concrete over many years and reach the reinforcing steel by capillary suction and absorption, pressure (usually hydrostatic), and diffusion (Mindess et al. 2003). In cracked concrete, the cracks provide quick access for these agents to the reinforcing steel, thus decreasing the structure's service life. The concrete early-age volume change, concrete material property development, and degree of restraint have been shown to be primary factors leading to early-age bridge deck cracking (Krauss and Rogalla 1996).

Early-age cracking can occur because of volume change that is restrained from movement. Early-age volume change in concrete occurs because of autogenous shrinkage, temperature changes, and plastic and drying shrinkage. Autogenous shrinkage occurs in low water-cementitious material ratio $(w / \mathrm{cm})$ concrete because there is not enough water available for complete hydration of the cement. As the cement hydration progresses, a water-vapor interface will form, leading to a capillary under pressure in the pores. The capillary under pressure in the pores causes a hoop stress in the pore wall, which consequently causes shrinkage (Mindess et al. 2003; Grasley 2006). Plastic and drying shrinkage occur because of moisture loss to the environment from concrete surfaces. Bridge decks are usually wet-cured during the first several days after placement with wet blankets and plastic, which minimizes or eliminates early moisture loss to the environment. For this reason, plastic and drying shrinkage were not considered in this study.

The internal temperature profile and the period of time during which the concrete heat dissipation takes place can greatly affect the early-age stress development (Krauss and Rogalla 1996; Mangold 1994). The concrete temperature change is the driving mechanism behind thermal stress development. Furthermore, the concrete mechanical property development is dependent on the concrete temperature. The concrete mechanical properties that are relevant for early-age stress development are the modulus of elasticity, the concrete coefficient of thermal expansion, Poisson's ratio, tensile strength, and creep during the first 24 to 36 hours after concrete placement (Springenschmid and Breitenbücher 1998). The rate of cement hydration is dependent on the temperature. The higher the temperature, the faster the cement will hydrate. Because mechanical properties are dependent on the cement hydration, they will develop faster at higher temperatures.

The degree of the bridge deck restraint directly affects the early-age concrete stress development. The concrete restraint is usually determined by the bridge configuration and construction sequence. The restraint can come from internal sources such as nonuniform temperature changes or drying shrinkage in the bridge deck. More importantly, the restraint can come from the girders changing volume at a different rate than the deck. This is caused by different temperature profiles, coefficients of thermal expansion, and/or different amounts of drying shrinkage in the deck and the girders. It is only when this concrete strain is restrained that stresses are generated.

Several studies have been performed in recent years that have included measuring the in-place bridge deck strains (Vurpillot et al. 1996; D'Ambrosia et al. 2005) limiting the use of in-place strain measurements to only a validation of predicted strains in computer simulations and not direct stress calculations from the concrete modulus and stress relaxation (D'Ambrosia et al. 2005). Krauss and Rogalla (1996) found that bridge decks built on large girders can have a final degree of restraint of approximately $60 \%$.

Rigid cracking frames have been used to quantify the relative impact of different materials, mixture proportions, and construction practices on thermal stresses (Springenschmid and Breitenbücher 1998). Figure 1 shows a schematic diagram and a photograph of a rigid cracking frame (RCF). A typical temperature and stress profile generated in the frame is shown in Fig. 2, where $T_{p c}$ is the temperature at the peak stress level, $T_{z, 2}$ is the temperature at the second zero stress point, and $T_{c}$ is the temperature at cracking (Springenschmid and Breitenbücher 1998). As the concrete temperature begins to increase due to the heat of hydration, the concrete will try to expand in proportion to the concrete coefficient of thermal expansion (CTE) and temperature. The concrete will

ACI Materials Journal, V. 106, No. 5, September-October 2009.

MS No. M-2008-248 received July 28, 2008, and reviewed under Institute publication policies. Copyright $(\odot) 2009$, American Concrete Institute. All rights reserved, including the making of copies unless permission is obtained from the copyright proprietors. Pertinent discussion including authors' closure, if any, will be published in the July-August 2010 ACI Materials Journal if the discussion is received by April 1, 2010. 
$\overline{\text { ACI member Kyle A. Riding is an Assistant Professor in the Department of Civil }}$ Engineering at Kansas State University, Manhattan, KS. He received his MSE and PhD from the University of Texas at Austin, Austin, TX.

ACI member Jonathan L. Poole is an Engineer at Wiss, Janney, Elstner Associates, Inc. He received his $B S, M S$, and PhD from the University of Texas at Austin. He is a member of ACI Committees 207, Mass Concrete, and 305, Hot Weather Concreting.

ACI member Anton K. Schindler is an Associate Professor in the Department of Civil Engineering at Auburn University, Auburn, AL. He received his MSE and PhD in civil engineering from the University of Texas at Austin.

ACI member Maria C. G. Juenger is an Associate Professor in the Department of Civil, Architectural, and Environmental Engineering at the University of Texas at Austin. She received her $P h D$ in materials science and engineering from Northwestern University, Evanston, IL. She is a member of ACI Committees 201, Durability of Concrete; 231, Properties of Concrete at Early Ages; and 236, Material Science of Concrete.

Kevin J. Folliard, FACI, is an Associate Professor in the Department of Civil, Architectural, and Environmental Engineering at the University of Texas at Austin. He received his $P h D$ in civil engineering from the University of California at Berkeley, Berkeley, CA, in 1995. He is Chair of ACI Committee 201, Durability of Concrete, and is a member of ACI Committees 318, Structural Concrete Building Code, and 350, Environmental Engineering Concrete Structures. He received the ACI Young Member Award for Professional Achievement in 2002.

not be able to expand because of the restraint provided by the cracking frame steel bars, effectively converting a portion of the expansive thermal strain into compressive thermal stress. Stress relaxation and the eventual decrease in temperature will reduce the compressive stress in the concrete until it reaches zero again, or the second zero stress point $T_{z, 2}$. A further decrease in the temperature will cause tensile stresses in the concrete to increase until the tensile stress exceeds the concrete tensile strength. Usually, insulation is provided in the formwork so that the temperature profile generated because of the concrete heat of hydration will simulate that of a $0.5 \mathrm{~m}$ $(1.64 \mathrm{ft})$ thick concrete member, and if the concrete has not cracked by 96 hours, the concrete is cooled externally by $1{ }^{\circ} \mathrm{C} / \mathrm{h}\left(1.8^{\circ} \mathrm{F} / \mathrm{h}\right)$ until it cracks, determining the cracking temperature $T_{c}$ (Mangold 1998).

During the first hours after the concrete sets, any temperature rise will lead to precompression in restrained concrete because of the thermal expansion. After the elastic modulus increases because of the increased degree of cement hydration and microstructural formation, creep and any temperature decreases will quickly relieve the concrete precompression and lead to the development of tensile stresses (Springenschmid and Breitenbücher 1998). The timing of any temperature increase or decrease in relation to the modulus development is critical. Rigid cracking frames are especially suited for examining concrete early-age stress development because they can capture the full effects of creep and modulus development from casting through setting and hardening.

The study reported in this paper focused on quantifying the effects of different materials and construction practices on early-age concrete stresses in bridge decks, focusing particularly on evaluating the effects of placement time and the concrete coefficient of thermal expansion. Rigid cracking frame testing, combined with the examination of early-age mechanical properties of the concrete, were used to jointly calculate the cracking tendency of different concrete placement scenarios.

\section{RESEARCH SIGNIFICANCE}

Bridge deck cracking is a major contributor to later chloride penetration and reinforcing steel corrosion. Early-age bridge deck cracking is caused by restrained thermal, autogenous, and drying shrinkage deformations. The early-age deformations, however, can also be used to partially prestress the concrete

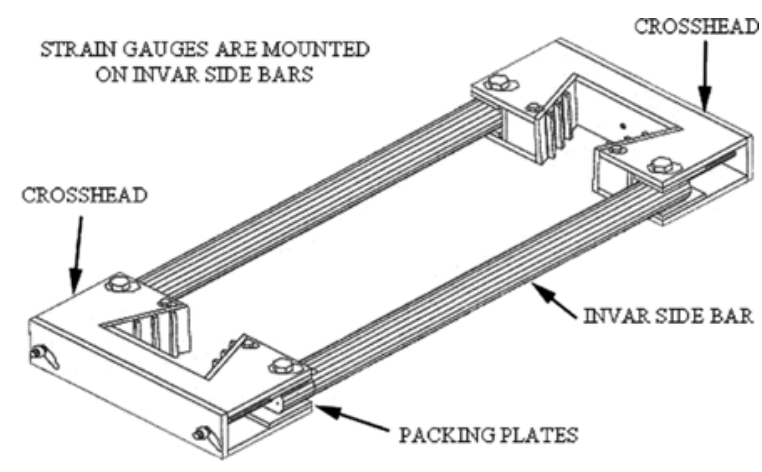

(a)

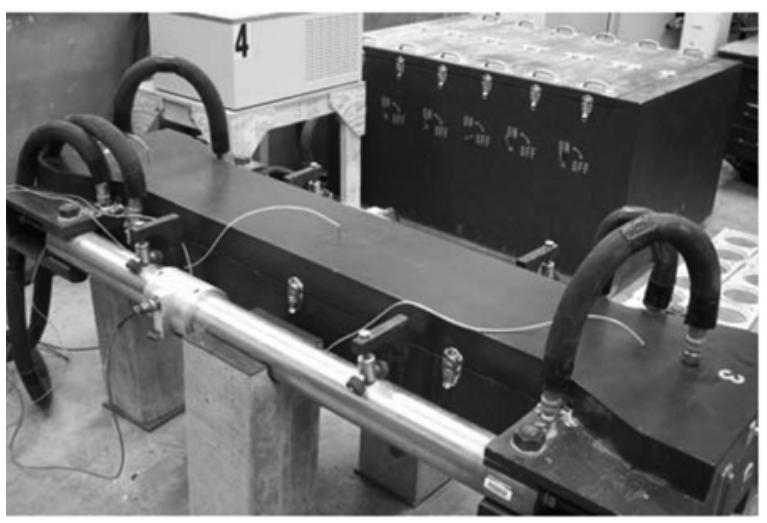

(b)

Fig. 1-Rigid cracking frame: (a) schematic of frame without crosshead braces and formwork; and (b) frame in use (Whigham 2005).



Fig. 2-Typical concrete temperature and thermal stress plot during routine cracking frame testing. (Note: $1 \mathrm{MPa}=$ $145 \mathrm{psi} ; 1^{\circ} \mathrm{C}=33.8^{\circ} \mathrm{F}$.)

bridge deck, lowering the risk of cracking. This paper presents an experimental method for examining how the material properties and construction methods influence the concrete stress development.

\section{EXPERIMENTAL WORK}

The experimental work performed was aimed at quantifying the potential contribution of thermal stresses to early-age bridge deck 
cracking. The first step in determining the potential for thermal stresses is determining the temperature history. To ensure that the thermal stresses measured during the restrained concrete testing would be representative of those possible in real bridge decks, a real bridge deck was instrumented and monitored for temperature development. The measured concrete bridge deck temperatures and those predicted for different placement times from the measured weather data were then used to evaluate the effects of different combinations of materials and placement times on concrete thermal stresses. A rigid cracking frame and match-cured concrete cylinders were used to quantify the thermal stress development possible in a bridge deck under these different scenarios.

\section{Bridge deck instrumentation}

The concrete for the bridge deck that was instrumented for temperature development was placed in Austin, TX on August 17, 2006. The weather during the bridge deck placement and curing period was monitored. Semi-adiabatic calorimetry testing was performed on the bridge deck concrete to obtain information on the heat produced during hydration (RILEM Technical Committee 119-TCE 1998). These data were used to predict the bridge deck temperature development with varying concrete placement times using a control-volumebased finite difference method. More detailed information on the temperature development model used can be found elsewhere (Riding et al. 2007a,b). The measured and predicted temperatures were then used as the concrete curing temperatures during the concrete thermal stress quantification testing.

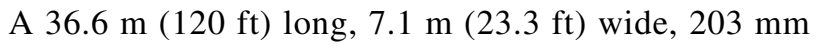
( 8 in.) thick single-span bridge was built next to the Ferguson Structural Engineering Laboratory at the University of Texas at Austin, Austin, TX as part of a separate research project. The

\section{Table 1-Location of temperature sensors in bridge deck}

\begin{tabular}{c|c|c|c}
\hline $\begin{array}{c}\text { Temperature } \\
\text { sensor }\end{array}$ & $\begin{array}{c}\text { Distance from } \\
\text { south side, } \mathrm{m}(\mathrm{ft})\end{array}$ & $\begin{array}{c}\text { Distance from } \\
\text { east side, } \mathrm{m}(\mathrm{ft})\end{array}$ & $\begin{array}{c}\text { Distance vertically } \\
\text { from bottom form, } \\
\mathrm{mm}(\mathrm{in} .)\end{array}$ \\
\hline Above east girder & $2.8(9.3)$ & $1.9(6.3)$ & $101(4)$ \\
\hline Between girders & $2.8(9.3)$ & $3.3(10.8)$ & $101(4)$ \\
\hline Vertical No. 1 & $9.0(29.7)$ & $3.5(11.3)$ & 0 \\
\hline Vertical No. 2 & $9.0(29.7)$ & $3.5(11.3)$ & $76(3)$ \\
\hline Vertical No. 3 & $9.0(29.7)$ & $3.5(11.3)$ & $178(7)$ \\
\hline
\end{tabular}

Table 2-Concrete properties

\begin{tabular}{c|c|c}
\hline Item & Content & Type \\
\hline Cement, $\mathrm{kg} / \mathrm{m}^{3}\left(\mathrm{lb} / \mathrm{yd}^{3}\right)$ & $260(439)$ & Type I/II \\
\hline Fly ash, $\mathrm{kg} / \mathrm{m}^{3}\left(\mathrm{lb} / \mathrm{yd}^{3}\right)$ & $88(149)$ & ASTM Class F \\
\hline $\begin{array}{c}\text { Coarse aggregate, } \mathrm{kg} / \mathrm{m}^{3}\left(\mathrm{lb} / \mathrm{yd}^{3}\right) \\
\text { Fine aggregate, } \mathrm{kg} / \mathrm{m}^{3}\left(\mathrm{lb} / \mathrm{yd}^{3}\right)\end{array}$ & $1127(1900)$ & $\begin{array}{c}1 \text { in. }(25 \mathrm{~mm}) \\
\text { dolomitic limestone }\end{array}$ \\
\hline $\begin{array}{c}\text { Air-entraining admixture, } \\
\text { mL/100 } \mathrm{kg}\left(\mathrm{oz} / \mathrm{cwt}^{3}\right)\end{array}$ & $19.6(0.3)$ & Natural sand \\
\hline $\begin{array}{c}\text { Water reducer } / \mathrm{retarder}, \\
\text { mL/100 kg (oz/cwt. }\end{array}$ & $189(2.9)$ & ASTM Type D \\
\hline Job-site measured air content & $2.6 \%$ & - \\
\hline $\begin{array}{c}\text { Job-site measured slump, mm (in.) } \\
\text { Design } w / \mathrm{cm}\end{array}$ & $75(3)$ & - \\
\hline
\end{tabular}

bridge was made up of $203 \mathrm{~mm}$ (8 in.) of cast-in-place concrete on permanent metal decking forms on two trapezoidal steel tub girders, as shown in Fig. 3. The bridge deck was placed beginning at approximately 7:00 a.m. and finished at approximately 11:00 a.m. on August 17, 2006. Temperature sensors were installed in the concrete bridge deck as shown in Fig. 4. The wires were attached and the temperature sensors were protected in epoxy using a previously described method (Riding et al. 2006). Some temperature sensors were placed in the vertical direction of the bridge deck as well as in the horizontal direction, over and between the steel tub girders. Table 1 shows the location of the sensors in the bridge deck. The concrete at the location of the temperature sensors above and between girders was placed at 10:00 a.m. The concrete at the location of the vertical temperature sensors was placed at 8:05 a.m.

A weather station for monitoring the ambient temperature, relative humidity, wind speed, and solar radiation was placed a few hundred yards from the construction site. The heat of hydration was also measured using semi-adiabatic calorimetry with concrete sampled on site.

Table 2 shows the concrete mixture design and fresh properties. Liquid nitrogen was used to cool the concrete to comply with the Texas Department of Transportation's (TxDOT) fresh concrete temperature specifications. Table 3 shows the chemistry of the cement used as calculated using both Bogue (ASTM C150 2005) and Rietveld methods (ASTM C1365 1998; Rietveld 1969). The fly ash used had a $\mathrm{CaO}$ content of $7.2 \%$. The fresh concrete temperature at placement was $28{ }^{\circ} \mathrm{C}\left(83^{\circ} \mathrm{F}\right)$. Curing blankets and black plastic were placed on top of the bridge deck and were kept in place for 10 days.

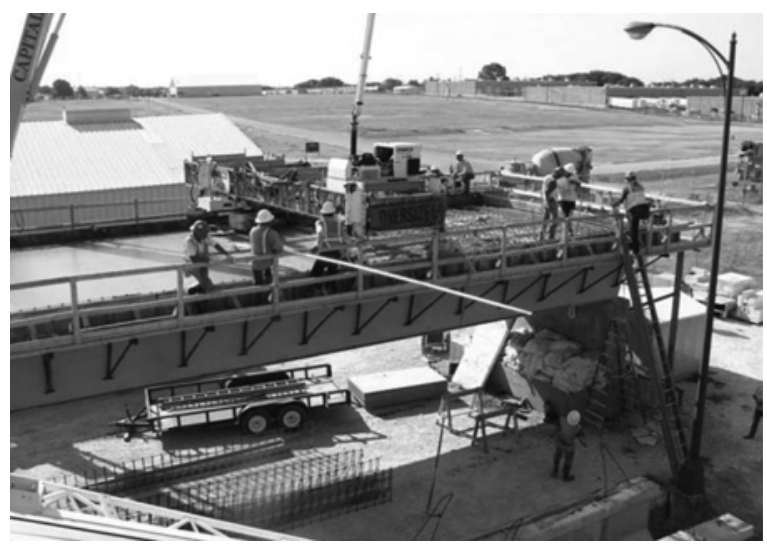

Fig. 3-Bridge during deck placement.

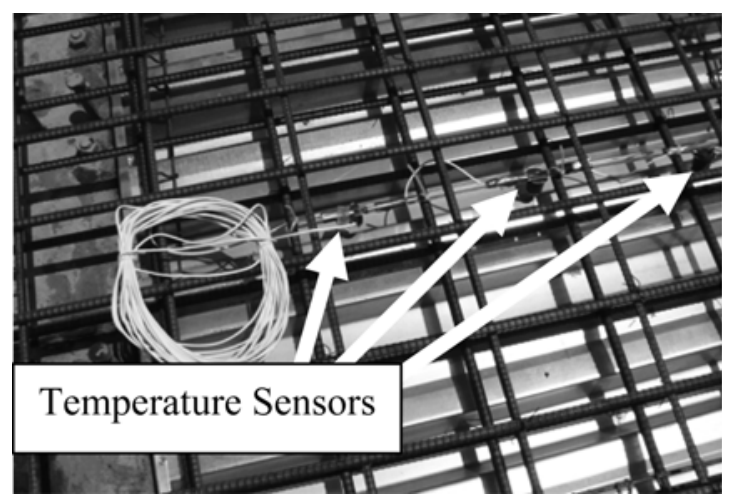

Fig. 4-Temperature sensors before concrete placement. 


\section{Stress testing procedure}

The actual thermal stresses in a bridge deck may be quite different than those measured in the rigid cracking frame because of differences in the degree of restraint provided by the girders, the temperature profile of the girders and bridge deck, and bending in the girders to maintain compatibility. The rigid cracking frame, however, can provide a quantitative comparison of material behavior at different temperature histories and material types that may help reduce thermal stresses in bridge decks.

The potential restrained concrete thermal stress development was tested using a rigid cracking frame (Mangold 1998). In this study, the cracking frame tests were performed using realistic bridge deck temperatures, measured and predicted, followed by cooling the concrete at $1{ }^{\circ} \mathrm{C} / \mathrm{h}\left(1.8^{\circ} \mathrm{F} / \mathrm{h}\right)$ after 96 hours. The measured and predicted bridge deck temperature history was imposed on the cracking frame specimen through a computer-controlled water circulator that was connected to pipes in the cracking frame formwork. The stress in the rigid cracking frame is monitored with strain gauges mounted on $100 \mathrm{~mm}$ (4 in.) diameter restraining bars. The degree of restraint provided by the bars on the concrete can be calculated using Eq. (1) (Mangold 1998)

$$
\delta=\frac{100}{1+\left(\frac{E_{c} A_{c}}{E_{s} A_{s}}\right)}
$$

where $\delta$ is the degree of restraint $(\%), E_{c}$ is the concrete elastic modulus (MPa), $A_{c}$ is the concrete cross-sectional area $\left(\mathrm{m}^{2}\right), E_{s}$ is the restraining bar modulus (MPa), and $A_{s}$ is the restraining bar's cross-sectional area $\left(\mathrm{m}^{2}\right)$. The temperature of the bars at the location of the strain gauges is measured using a resistance temperature detector (RTD) probe. The thermal movement of the restraining bars also needs to be subtracted from the measured strain to calculate the actual stress induced strain in the bars, as shown in Eq. (2)

$$
\varepsilon_{\text {Tadj }}=\Delta T_{i b} \cdot \alpha_{i b} \cdot \delta
$$

where $\varepsilon_{T a d j}$ is the temperature-induced strain of the bar, $\Delta T_{i b}$ is the temperature change of the bar at the strain gauge $\left({ }^{\circ} \mathrm{C}\right)$, and $\alpha_{i b}$ is the coefficient of thermal expansion of the bar $\left(\mathrm{m} / \mathrm{m} /{ }^{\circ} \mathrm{C}\right)$.

Twenty-four $100 \times 200 \mathrm{~mm}(4 \times 8$ in.) concrete cylinders were match-cured to the cracking frame temperature for mechanical property testing. The concrete cylinders were placed in an insulated water bath immediately after finishing. The temperature of the water bath was controlled within approximately $1{ }^{\circ} \mathrm{C}\left(1.8{ }^{\circ} \mathrm{F}\right)$ of the rigid cracking frame temperature by another $28 \mathrm{~L}\left(1 \mathrm{ft}^{3}\right)$ capacity refrigerating/ heating circulator. The cylinders were tested at 1/2, 1, 2, 3, 7, and 28 days for compressive strength (ASTM C39 2005), static modulus of elasticity (ASTM C469 2002), and splitting tensile strength (ASTM C496 2004). When a cylinder was removed from the water bath for testing, it was replaced with a "dummy" cylinder to maintain a constant water level. After 7 days of curing in the temperature-controlled water bath, the cylinders were removed from the molds and placed in a $100 \%$ relative humidity room. A water bath was also used to match-cure specimens for testing the time of setting of concrete mixtures by penetration resistance in accordance with ASTM C403 (2005). An additional cylinder was made for each mixture to measure the hardened concrete coefficient of thermal expansion according to AASHTO Provisional Standard TP60-00 (2001).

Concrete constituent materials were sampled from the batch plant on August 16, 2006, the day prior to the bridge deck placement. These materials were used in all of the cracking frame tests. One set of tests was performed that used the same materials, mixture proportions, and temperature history as found in the actual bridge deck (hereafter referred to as DL-10 a.m.; DL refers to the dolomitic limestone coarse aggregate). Two other sets of tests were performed using the same materials and mixture proportions but used the bridge deck temperatures predicted for a 2:00 p.m. (hereafter referred to as DL-2 p.m.) and a 10:00 p.m. placement time (hereafter referred to as DL-10 p.m.). A fourth set of tests was performed using the same temperature history measured in the actual bridge deck and with the same materials, except that siliceous river gravel coarse aggregates (RR) were used (hereafter referred to as RR-10 a.m.) instead of the DL used in the other tests. This RR has a much higher CTE than the limestone, so it was used to investigate the effects of concrete coefficient of thermal expansion on the thermal stresses developed. The specific gravity of the DL, sand, and RR was $2.74,2.66$, and 2.57 , respectively. To compensate for the different specific gravity of the river gravel compared to the limestone, the coarse aggregate and fine aggregate volumes of Mixture RR-10 a.m. were adjusted to maintain a constant coarse aggregate to total aggregate ratio. The coarse aggregate amount was adjusted to $1082 \mathrm{~kg} / \mathrm{m}^{3}\left(1824 \mathrm{lb} / \mathrm{yd}^{3}\right)$ and the fine aggregate amount was adjusted to $733 \mathrm{~kg} / \mathrm{m}^{3}\left(1235 \mathrm{lb} / \mathrm{yd}^{3}\right)$.

\section{Bridge deck}

RESULTS AND DISCUSSION

The weather during the bridge deck placement and curing was hot and dry. The weather monitoring station results showed that the relative humidity ranged from 25.3 to $84.7 \%$. The peak daily solar radiation ranged from 963 to $1079 \mathrm{~W} / \mathrm{m}^{2}$ (305 to $342 \mathrm{BTU} / \mathrm{h} / \mathrm{ft}^{2}$ ). The wind speed ranged from 0.4 to $6.9 \mathrm{~m} / \mathrm{s}$ ( 0.9 to $15.4 \mathrm{mph})$. Figure 5 shows the temperatures developed above and between the girders in the instrumented bridge deck. The temperature in the bridge deck was much higher above the girders than between them, because the girder trapped in heat that otherwise would have been lost due to convection under the deck. Figure 6 shows the temperature development through the deck cross section between the girders. The top temperature is shown as Sensor 3, the middle as Sensor 2, and the bottom as Sensor 1. The difference in temperature in the vertical direction was limited to less than $8{ }^{\circ} \mathrm{C}\left(14^{\circ} \mathrm{F}\right)$, mainly because of the

\section{Table 3-Cement chemistry}

\begin{tabular}{c|c|c}
\hline Item & Bogue analysis method & Rietveld analysis method \\
\hline $\mathrm{C}_{3} \mathrm{~S}$ (alite) & $45.2 \%$ & $58.5 \%$ \\
\hline $\mathrm{C}_{2} \mathrm{~S}$ (belite) & $26.9 \%$ & $13.8 \%$ \\
\hline $\mathrm{C}_{3} \mathrm{~A}$ (aluminate) & $7.5 \%$ & $6.2 \%$ \\
\hline $\mathrm{C}_{4} \mathrm{AF}$ (ferrite) & $10.1 \%$ & $10 \%$ \\
\hline $\mathrm{C} \overline{\mathrm{S}} \mathrm{H}_{2}$ (gypsum) & $4.35 \%$ & $1.6 \%$ \\
\hline $\mathrm{Hemihydrate}$ & - & $2.7 \%$ \\
\hline Anhydrite & - & $0.5 \%$ \\
\hline Periclase & - & $0.9 \%$ \\
\hline $\mathrm{K}_{2} \mathrm{SO}_{4}$ & - & $1.3 \%$ \\
\hline $\mathrm{CaCO}_{3}$ & - & $3.2 \%$ \\
\hline
\end{tabular}


insulation provided by the curing blanket on the deck. The bottom of the deck tended to be cooler than the top of the deck, because of the lack of insulation underneath the deck, and the solar radiation component that influences the top more than the bottom. The temperature measured between the girders at middepth, as shown in Fig. 5, was selected to be used as the target temperature history of rigid cracking frame stress tests DL-10 a.m. and RR-10 a.m. The temperature between the girders was selected because the temperature prediction model used to predict the temperature history at different concrete placement times assumes that the concrete is open below the bridge deck.

Figure 7 shows the adiabatic temperature development curve calculated from the semi-adiabatic calorimetry data obtained from the concrete sampled at the bridge deck placement. The semi-adiabatic calorimetry data and measured weather data were used to predict the temperature of the bridge deck if the placement had started at 2:00 p.m. or 10:00 p.m. The predicted temperatures for the 2:00 p.m. and 10:00 p.m. placement times were used as the target temperature histories for rigid cracking frame tests DL-2 p.m. and DL-10 p.m.

The rigid cracking frame temperatures measured in the middle of the specimen versus the simulated time of day of the test are shown in Fig. 8(a). These temperatures start when the mixture would have been placed, and end when the concrete cracked, except in the case of DL-10 p.m., in which case the test was stopped before cracking. The corresponding cracking frame measured stresses versus the simulated time of day are shown in Fig. 8(b). The degree of restraint of the

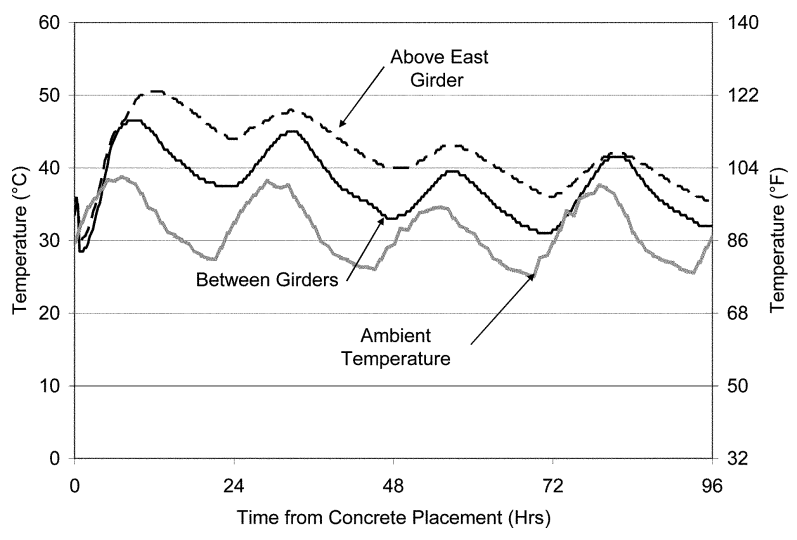

Fig. 5-Temperature development in bridge deck at middepth above and between girders.



Fig. 6-Vertical temperature profile in bridge deck between girders. cracking frame began at $100 \%$ during the fresh plastic state, and for all tests decreased to $77 \%$ at the time of cracking.

Figure 9 shows the: a) compressive strength development; b) elastic modulus development; and c) splitting tensile strength development of the mixtures tested. The mixtures showed very similar modulus development, but the test RR-10 a.m. showed slightly lower compressive and splitting tensile strengths. This is probably because of the smooth surface texture of the siliceous river gravel particles as compared to the rough texture of the crushed dolomite aggregates.

Figure 10 shows the rigid cracking frame measured stress history divided by the measured tensile strength development. The specimens cracked at a stress-to-splitting tensile strength ratio of between 0.61 and 0.68 . The specimens cracked at a ratio less than 1.0 because of the following reasons: 1) the splitting tensile strength overestimates the

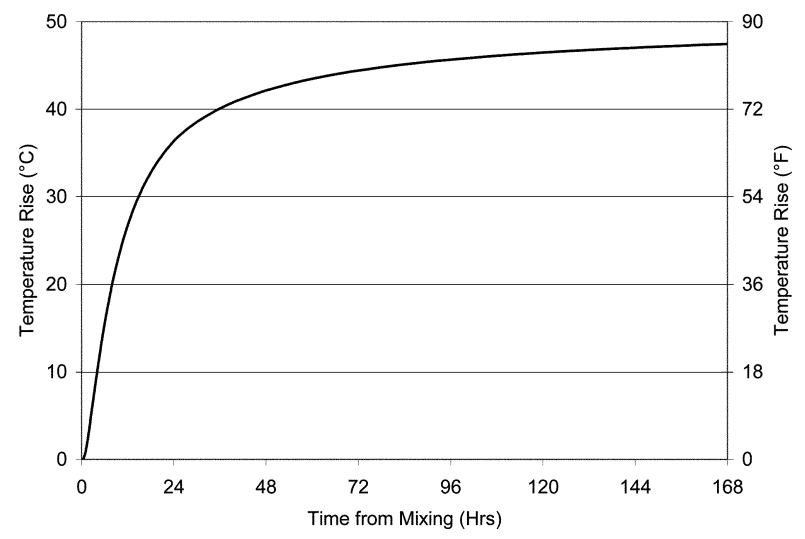

Fig. 7-Adiabatic temperature rise for concrete used in bridge deck.


Fig. 8-Rigid cracking frame test data: (a) middle temperatures; and (b) stress development. 
direct tensile strength (Mindess et al. 2003); 2) the rapid loading rate of the splitting tensile test gives a higher measured tensile strength than the true concrete tensile strength when loaded slowly, as is the case with thermal stresses (Emborg 1998); and 3) the size effect between the $100 \times 200 \mathrm{~mm}(4 \times 8$ in.) concrete cylinders and the $150 \times 150 \mathrm{~mm}(6 \times 6$ in.) rigid cracking frame specimen cross section gives higher measured tensile strength values in the smaller splitting tensile strength specimen (Shah et al. 1995). The concrete stress at cracking as measured in the cracking frame may be more indicative of the bridge deck concrete's resistance to cracking than the splitting tensile strength because of these reasons.

The measured hardened coefficient of thermal expansion for each concrete mixture is shown in Table 4. There is some variation in the results between tests DL-10 a.m., DL-2 p.m., and
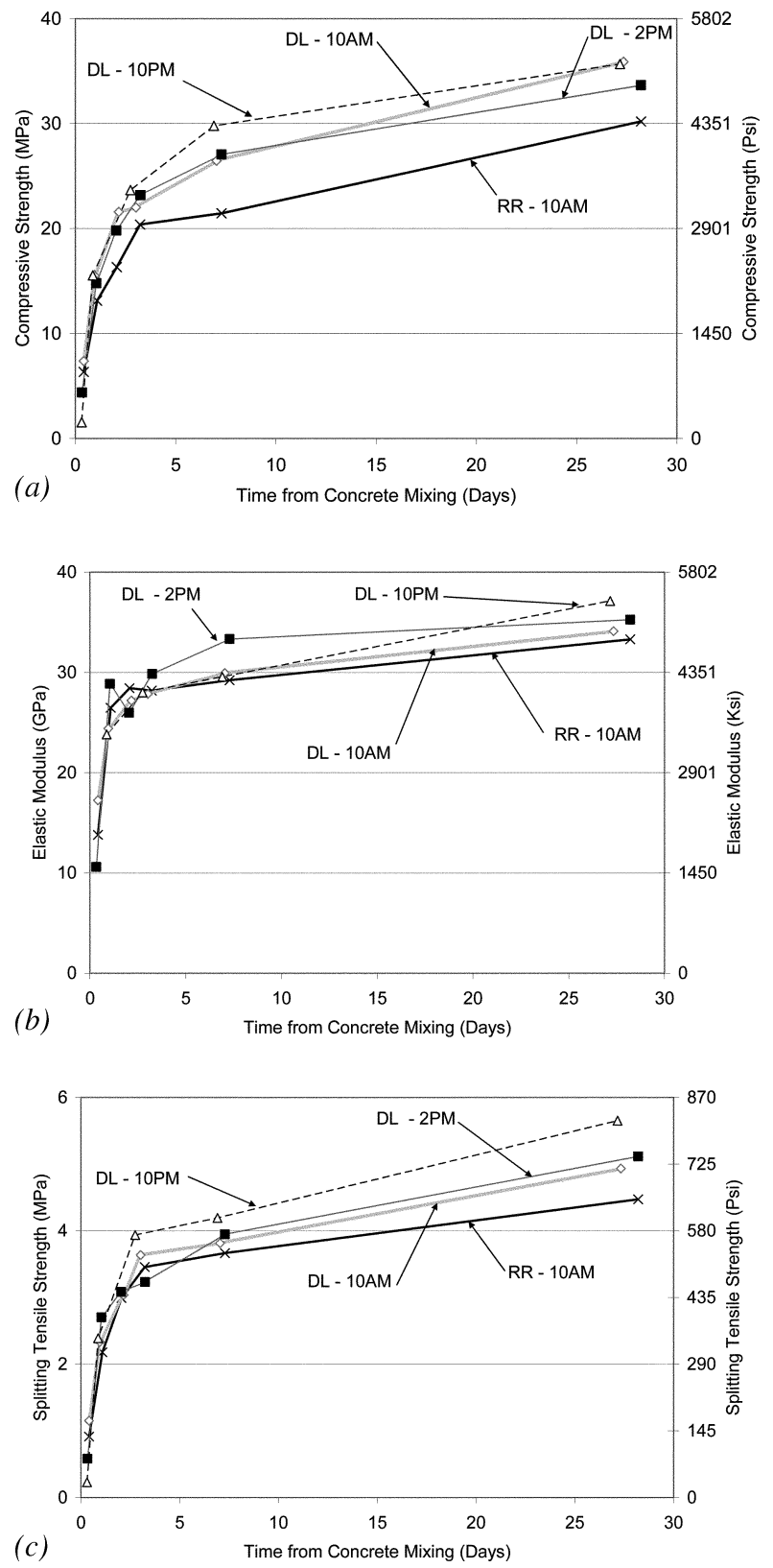

Fig. 9-Concrete mechanical property development: (a) compressive strength development; (b) elastic modulus development; and (c) splitting tensile strength development.
DL-10 p.m., but within the $0.5 \mu \varepsilon /{ }^{\circ} \mathrm{C}\left(0.4 \mu \varepsilon /{ }^{\circ} \mathrm{F}\right)$ tolerance expected between the heating and cooling portions of the test. The coefficient of thermal expansion of Test RR-10 a.m. is $33 \%$ greater than the average of tests DL-10 a.m., DL-2 p.m., and DL-10 p.m.

\section{Discussion of results}

The concrete thermal stress develops as a result of the interaction between the modulus development, coefficient of thermal expansion, temperature change, high early-age creep, and restraint. As shown in Fig. 8, Test DL-10 p.m. developed a large compressive stress during the first 24 hours after placement when compared to tests DL-10 a.m. and DL-2 p.m. This occurred because the concrete set before the significant temperature increase occurred. Any temperature rise before the time of set will not result in a beneficial compressive stress because the modulus is so low. The concrete will still have to cool down during the diurnal cycle, giving tensile stresses in the concrete. When the time of placement is such that the concrete sets before the rise in temperature from the heat of hydration and diurnal cycle, the heating will result in compressive stresses that will partially offset some of the tensile stresses that occur when the concrete inevitably cools down. This precompression from the night placement lowered the subsequent tensile stresses that developed, even though the mixture experienced a larger temperature decrease than the other mixtures during the second day of testing. Because the maximum tensile stress was low, the risk of thermal cracking is less than for the other conditions.

The mixture containing river gravel showed significantly higher stresses than the mixtures containing DL. As shown in Fig. 8, the measured stress in test RR-10 a.m. was 32\% larger than that in DL-10 a.m., 52\% larger than that measured in DL-2 p.m., and $110 \%$ larger than that measured in DL-10 p.m. Additionally, casting the concrete at 10 p.m. versus $10 \mathrm{a} . \mathrm{m}$. lowered the concrete tensile stresses by $46 \%$ at 2 days and $36 \%$ at 4 days, demonstrating that the tensile

\section{Table 4-Hardened coefficient of thermal expansion test results}

\begin{tabular}{c|c}
\hline Test ID & Coefficient of thermal expansion, $\mu \varepsilon /{ }^{\circ} \mathrm{C}\left(\mu \varepsilon /{ }^{\circ} \mathrm{F}\right)$ \\
\hline DL-10 a.m. & $7.8(4.3)$ \\
\hline DL-2 p.m. & $7.5(4.1)$ \\
\hline DL-10 p.m. & $8.0(4.4)$ \\
\hline RR-10 a.m. & $10.4(5.8)$ \\
\hline
\end{tabular}



Fig. 10-Rigid cracking frame measured stress/splitting tensile strength. 
stresses' development in concrete can be lowered using multiple strategies. This indicates that both the time of placement and the coefficient of thermal expansion are significant parameters in avoiding thermal cracking. Also, at 96 hours after mixing, the measured tensile stress in test RR-10 a.m. was at $1.7 \mathrm{MPa}$ (243 psi); this specimen cracked at a stress level of $2.2 \mathrm{MPa}$ (322 psi). This means that test RR-10 a.m. was at $75 \%$ of the cracking stress 96 hours after mixing (or 10 a.m. on August 21, 2006) and before the final cooling began, indicating that the river gravel mixture was quite susceptible to cracking. Just by using a coarse aggregate with a higher coefficient of thermal expansion and placing the concrete in the daytime rather than at night, the tensile stresses significantly increased.

\section{CONCLUSIONS}

Rigid cracking frame testing performed under realistic bridge deck temperature histories was used to quantitatively compare the relative early-age behavior of different concrete materials and placement times that may help reduce earlyage concrete bridge deck stresses. The thermal component of bridge deck early-age stresses can be significant. In the case of the test simulating a morning placement with a concrete with a high coefficient of thermal expansion, the early-age thermal stresses were found to be as much as $75 \%$ of the cracking stress. The river gravel aggregate had a 33\% larger concrete coefficient of thermal expansion, which fully accounts for the $32 \%$ higher tensile stresses than when the limestone aggregate was used. Casting the concrete at 10:00 p.m. versus 10:00 a.m. under this simulated temperature scenario lowered the concrete tensile stresses by $46 \%$ at 2 days and $36 \%$ at 4 days. The testing found that the early-age thermal stresses were reduced by up to $50 \%$ by using a coarse aggregate with a lower coefficient of thermal expansion and placing the concrete at night. The testing performed herein does not necessarily represent the actual stresses seen in a bridge deck, but the potential stresses. Real bridge deck stresses will be affected by the degree of restraint in the deck and bending that occurs in the deck and girders due to the nonuniform temperature changes in the bridge deck with location and depth. The methods in this paper may be used to further investigate the role of concrete material properties, temperature effects, and construction sequencing on bridge deck cracking. More research is also needed in modeling bridge deck cracking due to these differences between the simulated stresses and actual stresses.

\section{ACKNOWLEDGMENTS}

The authors wish to express their gratitude to the Texas Department of Transportation (TxDOT) through Project 0-4563 for funding this research. The assistance of S. Slatnick in performing the cracking frame and mechanical property tests is kindly acknowledged. The guidance and assistance of R. Springenschmid and E. Gierlinger to develop the cracking frame test setup are appreciated. The authors also wish to thank K. Frank, T. Barnard, and C. Hovell for arranging access to the bridge deck. The authors would also like to thank K. Scrivener and C. Gosselin for performing the Rietveld analysis on the portland cement used.

\section{NOTATION}

$A_{c}=$
$A_{s}=$
$E_{c}=$
$E_{s}=$
$\alpha_{i b}=$
$\Delta_{T i b}=$
$\delta=$
$\varepsilon_{\text {Tadj }}=$
concrete cross-sectional area
bar cross-sectional area
concrete elastic modulus
bar modulus
coefficient of thermal expansion of bar
temperature change of bar at strain gauge bar
degree of restraint
temperature-induced strain of bar

\section{REFERENCES}

AASHTO TP60-00, 2001, "Proposed Standard Test Method for the Coefficient of Thermal Expansion of Hydraulic Cement Concrete," American Association of State Highway and Transportation Officials, Washington, DC, pp. 584-590.

ASTM C39/C39M, 2005, "Standard Test Method for Compressive Strength of Cylindrical Concrete Specimens," ASTM International, West Conshohocken, PA, 7 pp.

ASTM C150, 2005, "Standard Specification for Portland Cement," ASTM International, West Conshohocken, PA, 8 pp.

ASTM C403/C403M, 2005, "Standard Test Method for Time of Setting of Concrete Mixtures by Penetration Resistance," ASTM International, West Conshohocken, PA, 7 pp.

ASTM C469, 2002, "Standard Test Method of Static Modulus of Elasticity and Poisson's Ratio of Concrete in Compression," ASTM International, West Conshohocken, PA, 5 pp.

ASTM C496/C496M, 2004, "Standard Test Method for Splitting Tensile Strength of Cylindrical Concrete Specimens," ASTM International, West Conshohocken, PA, 5 pp.

ASTM C1365, 1998, "Standard Test Method for Determination of Proportion of Phases in Portland Cement and Portland-Cement Clinker Using X-Ray Powder Diffraction Analysis," ASTM International, West Conshohocken, PA, $10 \mathrm{pp}$.

D’Ambrosia, M. D.; Lange, D. A.; Grasley, Z. C.; Roesler, J. R.; Lee, C. J.; and Altoubat, S. A., 2005, "Instrumentation and Analysis of HighPerformance Concrete Bridge Decks," Transportation Research Record, V. 1914, pp. 85-96.

Emborg, M., 1998, "Developing Early Age Mechanical Behaviour,' Rilem Report 15, Prevention of Thermal Cracking in Concrete at Early Ages, R. Springenschmid, ed., E\&FN Spon, London, UK, pp. 76-148.

Grasley, Z. C., 2006, "Measuring and Modeling the Time-Dependent Response of Cementitious Materials to Internal Stresses," doctoral thesis, The University of Illinois at Urbana Champaign, Urbana, IL, 238 pp.

Krauss, P. D., and Rogalla, E. A., 1996, "Transverse Cracking in Newly Constructed Bridge Decks," NCHRP Report 380, Transportation Research Board, National Research Council, Washington, DC, 132 pp.

Mangold, M., 1994, "Thermal Prestress of Concrete by Surface Cooling," Rilem Report 25, Thermal Cracking in Concrete at Early Ages, R. Springenschmid, ed., E\&FN Spon, London, UK, pp. 265-272.

Mangold, M., 1998, "Methods for Experimental Determination of Thermal Stresses and Crack Sensitivity in the Laboratory," Rilem Report 15, Prevention of Thermal Cracking in Concrete at Early Ages, R. Springenschmid, ed., E\&FN Spon, London, UK, pp. 26-39.

Mindess, S.; Young, J. F.; and Darwin, D., 2003, Concrete, second edition, Pearson Education, Inc., Upper Saddle River, NJ, 644 pp.

Riding, K. A.; Poole, J. L.; Schindler, A.K.; Juenger, M. G.; and Folliard, K. J., 2006, "Evaluation of Temperature Prediction Methods for Mass Concrete Members,' ACI Materials Journal, V. 103, No. 5, Sept.-Oct., pp. 357-365.

Riding, K. A.; Poole, J. L.; Schindler, A. K.; Juenger, M. G.; and Folliard, K. J., 2007a, "Calorimetry Performed On-Site: Methods and Uses," Concrete Heat Development: Monitoring, Prediction \& Management, SP-241, K. Wang and A. Schindler, eds., American Concrete Institute, Farmington Hills, MI. (CD-ROM)

Riding, K. A.; Poole, J. L.; Schindler, A. K.; Juenger, M. G.; and Folliard, K. J., 2007b, "Temperature Boundary Condition Models for Concrete Bridge Members," ACI Materials Journal, V. 104, No. 4, July-Aug., pp. 379-387.

Rietveld, H. M., 1969, "A Profile Refinement Method for Nuvlear and Magnetic Structure,” Journal of Applied Crystallography, V. 2, pp. 65-71.

RILEM Technical Committee 119-TCE, 1998, "Adiabatic and SemiAdiabatic Calorimetry to Determine the Temperature Increase in Concrete due to Hydration Heat of Cement," Rilem Report 15, Prevention of Thermal Cracking in Concrete at Early Ages, R. Springenschmid, ed., E\&FN Spon, London, UK, pp. 315-330.

Shah, S. P.; Swartz, S. E.; and Ouyang, C., 1995, Fracture Mechanics of Concrete: Applications of Fracture Mechanics to Concrete, Rock and Other Quisi-Brittle Materials, Wiley, New York, 592 pp.

Springenschmid, R., and Breitenbücher, R., 1998, "Influence of Constituents, Mix Proportions and Temperature on Cracking Sensitivity of Concrete," Rilem Report 15, Prevention of Thermal Cracking in Concrete at Early Ages, R. Springenschmid, ed., E\&FN Spon, London, UK, pp. 40-50.

Vurpillot, S.; Inaudi, D.; and Ducret, J. M., 1996, "Bridge Monitoring by Fiber Optic Deformation Sensors: Design, Emplacement, and Results," Proceedings of the SPIE, V. 2719, pp. 141-149.

Whigham, J., 2005, "Evaluation of Restraint Stresses and Cracking in Early-Age Concrete with the Rigid Cracking Frame," master's thesis, Auburn University, Auburn, AL, pp. 169 and 192. 